\title{
Nurse, nurse...
}

\author{
Stephen Hancocks OBE \\ Editor-in-Chief
}

The BDJ Upfront section includes editorials, letters, news, book reviews and interviews. Please direct your correspondence to the News Editor,

Kate Quinlan at k.quinlan@nature.com. Press releases or articles may be edited, and should include a colour photograph if possible.

W ords have such distinct cultural connotations. The repetition 'nurse, nurse...' conveys an urgency, a need, an entreaty for help. 'Doctor, doctor...' by comparison sounds like the beginning of a joke. 'Dentist, dentist...' holds no immediate additional sense at all. How strange.

The current issue of BDJ Team (https:// go.nature.com/3I8IQus), the biggest on record, focuses on dental nurses and provides as contemporaneous, comprehensive and telling a summary of the state of the profession as one is likely to find. It does so in 20 feature articles by recording the real-life experiences of those who, arguably, are our most important and yet most overlooked and undervalued colleagues.

What runs so strongly through the personal narratives is the loyalty and devotion to the nurses' roles and practices. Many of them are breadwinners and more than a few require a second job to make ends meet. As clichéd an observation as it may be, there is often little or no gap between the wages paid to dental nurses and those to shelf-filling supermarket staff. It can only therefore be the love of their work, their care for patients and dedication to the practice and other dental team members that motivates them to get up at, in some cases, yawningly early hours, miss breakfast, travel miles, work the whole day and repeat the process day-in, week-out. As surely as this is admirable, it is also unacceptable.

There is considerable current debate as to whether or not a recruitment crisis exists in dental nursing. On the one hand, GDC data indicated a drop-off in numbers renewing their registration at year-end in August of this year, while others point to this not being unusual and shrugging it off as a blip. What is significant is that the data have initiated the employment gap as a possibility and that the inclusion of other information from real world experience may cause us to put two and two together. How were dental nurses treated during the early period of the pandemic and the lockdowns, for example? Details of poor employment practices have emerged with DCPs not being paid to furlough or even being dismissed. However, articles in BDJ Team indicate that even prior to the current situation, very few employers provided payment of GDC annual registration fees, indemnity cover and/or time off or resources for mandatory CPD requirements. Does this really indicate a sincerity to include members of a profession in an effective team?

The finances of employing dental nurses are of course inevitably intertwined with the what seems like an unusually high number of treasured colleagues we have lost in 2021. My thoughts go out to friends, families and colleagues who have been bereaved in recent times; the profession too is the poorer for their passing.

This also provides me with the opportunity to say thank you to the amazing editorial, production and sales teams who work for the $B D J$ and the Portfolio. So much happens behind the scenes meaning that, once again this year, they have helped create 53 issues of our six publications as well as 35 new papers in the online-only BDJ Open, which by its nature has no issues as such but a rolling schedule. What is particularly remarkable is that every one of these publications has

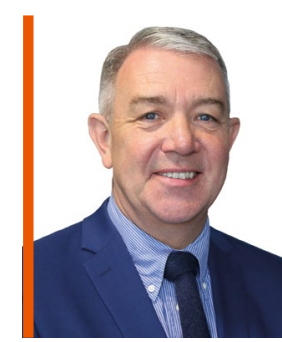

\section{'If we really value the work of dental nurses and expect our patients to do the same, then we also have to boost their status to a level commensurate with their actual worth.'}

state of the NHS general dental contract as well as the economics of private practice. Yet, if we really value the work of dental nurses and expect our patients to do the same, then we also have to boost their status to a level commensurate with their actual worth. That needs to be both spoken and unspoken by dint of communication and attitude. If we cry 'nurse, nurse...' with the imploring urgency of a call for help and care, we need also to pay due respect literally and metaphorically to fulfilling our duty to care for them in turn, materially and spiritually.

\section{The turning year}

The next $B D J$ is a caries focused issue with a guest editor, so this is my last editorial of the year. I wanted to take a moment to reflect on been published on time and in full with every single team member working from home. Needless to say, this is a unique milestone in our history and one for which I am not only deeply grateful but one of which I am in awe. Thank you all.

To round off another 12 months, I would also like to wish you the reader and all our other stakeholders a very Happy Holiday Season. Dentistry in the UK, and around the world, has been through another testing and difficult pandemic-fractured year of restraints, constraints and challenges as we grapple with the best ways in which to care for our patients. So, it is with admiration and respect that I wish to all a Merry Christmas and a Happy, Healthy and Prosperous 2022.

https://doi.org/10.1038/s41415-021-3728-y 